\title{
Germanica
}

dans la littérature, le cinéma et le théâtre

\section{Gabriele Tergit, Vom Frühling und von der Einsamkeit. Reportagen aus den Gerichten}

\section{Helmut Pillau}

\section{CpenEdition}

\section{Journals}

Édition électronique

URL : https://journals.openedition.org/germanica/11218

DOI : 10.4000/germanica. 11218

ISSN : 2107-0784

Éditeur

Université de Lille

Édition imprimée

Date de publication : 28 juin 2021

Pagination : 195-198

ISBN : 978-2-913857-47-6

ISSN : 0984-2632

Référence électronique

Helmut Pillau, "Gabriele Tergit, Vom Frühling und von der Einsamkeit. Reportagen aus den Gerichten", Germanica [Online], 68 | 2e trimestre 2021, Online erschienen am: 28 Juni 2021, abgerufen am 04 Januar 2023. URL: http://journals.openedition.org/germanica/11218 ; DOl: https://doi.org/10.4000/ germanica. 11218

Ce document a été généré automatiquement le 4 janvier 2023

All rights reserved 


\title{
Gabriele Tergit, Vom Frühling und von der Einsamkeit. Reportagen aus den Gerichten
}

\author{
Helmut Pillau
}

\section{RÉFÉRENCE}

Gabriele Tergit, Vom Frühling und von der Einsamkeit. Reportagen aus den Gerichten, Hrsg. und mit einem Nachwort von Nicole Henneberg, Frankfurt a. M., Schöffling \& Co, 2020.

1 Wie Erich Kästner, Kurt Tucholsky und Irmgard Keun gehört auch Gabriele Tergit zu den Autoren und Autorinnen, die für die Weimarer Republik repräsentativ sind. Sie, die 1884 in Berlin geborene Jüdin, wusste genau, wie fragil dieser erste Versuch einer Demokratie auf deutschem Boden war. Sie ließ sich aber nicht vom Furor der Widersacher dieser Republik irritieren und vertraute stattdessen unverdrossen der stillen Kraft der Vernunft.

Gabriele Tergit, geborene Hirschmann und verheiratete Reifenberg, versteht sich als leidenschaftliche Journalistin. Bekannt wurde sie in Berlin durch ihre Gerichtsreportagen, die sie im Berliner Börsen Courier, der Weltbühne und vor allem in „ihrem“ Berliner Tageblatt veröffentlichte. 1931 erregte sie Aufsehen mit ihrem Roman Käsebier erobert den Kurfürstendamm, der im Zeitungsmilieu spielt. Dieser Roman und vor allem ihr Roman Effingers, den sie hauptsächlich im Exil schrieb, sind in den letzten Jahren wiederentdeckt worden und haben einen großen Anklang gefunden. Dies führte dazu, dass 2020 eine 121 Texte umfassende Auswahl ihrer Gerichtsreportagen im Frankfurter Schöffling-Verlag erschien. Nicole Henneberg, eine ausgewiesene Kennerin von Tergits Werk, gab dieses Buch heraus und versah es mit einem Nachwort.

Erfolg hatte Tergit in Berlin mit ihren Gerichtsreportagen wohl auch deswegen, weil sie einen neuen, für dieses Genre ungewöhnlichen Ton anschlug. Was ihre Sprache betrifft, 
meint man darin die eigentümliche Berliner Sprechweise mit ihrer Nüchternheit, Lässigkeit und witzigen Pointiertheit zu vernehmen. Dadurch gewann die Autorin von vornherein eine gewisse Distanz zur einschüchternden Autorität der Institution, der ihre Texte galten. Statt aber diese Institution, also das Gerichtswesen, aus einem radikalen Impuls heraus in Frage zu stellen, bejahte sie dieselbe prinzipiell und damit den Rechtsstaat. Sie wusste genau, dass die nach 1919 in Deutschland gewonnenen neuen demokratischen Freiheiten auf einen rechtlichen Rahmen angewiesen waren. Am Herzen lag ihr aber, einer Verknöcherung des Rechtswesens entgegenzuwirken: Durch eine Konfrontation mit der Lebenswirklichkeit sollte es lebensnäher werden; auch sollte der latente Rechtsdrall der Justiz offenbar werden.

Dass die Gesetze gelegentlich nicht, wie sie verheißen, dem Leben beistehen, sondern es blockieren, registriert Tergit bei Gerichtsverhandlungen. Eher komisch wirkt es etwa, wenn Richter sich mit frustrierten älteren Damen („dürren Verwelkten“, S.9) verbünden, die vermeintlich unsittlich handelnde junge Paare ausspionieren. Angesichts drakonischer Urteile wird ihr auch bewusst, wie weit sich bestimmte Gesetze - gegen die „Kuppelei“ und die „Unzucht“- von den selbstverständlich gewordenen Sitten der Gegenwart entfernt haben. So fragt sie: „Hält das Gesetz noch Schritt mit dem Leben?" (S. 111) Besonders engagiert wirkt sie, sobald sie sich mit dem $\S 218$ und seinen ruinösen Folgen, also dem Gesetz gegen die Abtreibung, auseinandersetzt. Während man bis heute damit noch nicht recht zu Rande gekommen zu sein scheint, ist gegenwärtig zumindest der von ihr gleichfalls bekämpfte $§ 175$, also die Sanktionierung homosexueller Handlungen, abgeschafft worden.

5 Als Zeitgenossin ist Gabriele Tergit wohl bewusst, wie leicht Menschen ohne kriminelle Anlagen durch den Krieg und die Inflationszeit auf die schiefe Ebene geraten konnten. Um Betrügereien, Unterschlagungen, Urkundenfälschungen und Falschmünzerei geht es. Sie plädiert in Fällen dieser Art dafür, nicht nur an eine korrekte Anwendung der Gesetze, sondern auch an die "Menschlichkeit" (S. 49) zu denken. Angesichts eines Falles von Bigamie, den Wirren der Nachkriegszeit geschuldet, schwingt sie sich 1928 sogar zu der allgemeinen Forderung auf: „Amnestie müsste sein für alles, was geschah zwischen 1914 und 1924." (S. 131)

Sie hat einen scharfen Blick dafür, wie wenig manchmal Gesetze diffizileren Fällen gerecht werden können. Für zwar labile, aber eigentlich gutartige Straftäter schlägt sie witzig „Bewährungsanstalten für Harmlose“ (S. 45) anstelle der konventionellen Gefängnisse und Irrenanstalten vor. Es empört sie auch, wie unsensibel die Behörden mit dem Problem der Jugendbanden, einem typischen Phänomen der chaotischen Nachkriegszeit, umgehen: „Der Apparat tötet die Menschen, treibt den, der guten Willens ist, dem Verbrechen in die Arme." (S. 287) Bezeichnend scheint mir zu sein, dass sie solche scharfen Töne in der besonders gesellschaftskritischen Weltbühne, der von Carl von Ossietzky herausgegebenen Zeitschrift, anschlägt. Dort erscheint auch am 28. 2. $1933 \mathrm{ihr}$ Artikel über einen Prozess gegen Fritz Brolat, Direktor der BVG („Berliner Verkehrsbetriebe“), der wegen Korruption angeklagt wird. Tergit erwähnt das Interesse rechter Kreise daran, Brolat, prominentes Mitglied der SPD, zu Fall zu bringen. Obwohl sie eigentlich mit der SPD sympathisiert, spiegelt sich aus ihrer Sicht in Brolats Fall doch auch die Problematik eines Aufsteigers ohne genügendes Klassenbewusstsein wider. Vielleicht allzu schnell war Brolat vom Schlosser zum prominenten Politiker der SPD und schließlich Direktor der BVG aufgestiegen: „Brolat ist die Verkörperung vom Glanz und Abstieg einer großen Bewegung, der Proletarier, 
der Kleinbürger wurde, satt und sehnsuchtslos.“ (S. 293) Sie berührt damit die Achillesferse dieser linken Partei.

7 Tergit lotet in ihren Reportagen nicht nur Untiefen der deutschen Gesellschaft aus, sondern berichtet gelegentlich auch von skurrilen Fällen. Humorvoll schildert sie, wie sich geniale Betrüger, Wahrsagerinnen und Heiratsschwindler die Leichtgläubigkeit vereinsamter Menschen zu Nutze machen. Neugierig liest man ihre Reportage über einen Prozess mit ihrem prominenten Berliner Kollegen Alfred Döblin. Dieser kam vor Gericht, weil sich sein Zahnarzt durch einen Artikel Döblins über eine verunglückte Zahnbehandlung - Döblin: „[ein] Erlebnis mit dem Hintergrund eines schweren Verhängnisses“ - verunglimpft fühlte (S. 119).

8 Tergit erlaubt es sich aber auch gelegentlich, von den Vorgängen im Gericht Abstand zu nehmen und allgemeinere Betrachtungen in essayistischer Form anzustellen. So reflektiert sie darüber, wie sich Männer und Frauen bei Gewalttaten aus Liebe voneinander unterscheiden: „Wer schießt aus Liebe?“ (S. 243-346) Humorvoll versucht sie sich auch darin, eine Typologie von Zuhörern und Wachtmeistern im Gericht zu entwerfen.

9 Gabriele Tergit wusste, dass allzu viele in Deutschland die Gewalt für ein legitimes Mittel der politischen Auseinandersetzung hielten. Dies spiegeln ihre diversen Berichte über Prozesse wider, die sich um brachiale Konflikte zwischen politischen Kontrahenten, meist Nazis und Kommunisten, drehen. Zunächst sah sie in den Kämpfern gegen die Republik Männer, die ihre Militarisierung durch den Krieg noch nicht überwunden hatten. Später beobachtete sie, dass sich die politischen Konflikte zunehmend vom Parlament auf die Straße verlagerten. Manche Richter gingen ihrer Meinung nach allzu nachsichtig mit den Nazi-Tätern um: „So zart kann man das Faustrecht, das sich in Deutschland ausbreitet, nicht bekämpfen." (S. 186) Mut schöpfte sie dagegen in einem anderen Prozess vom Oktober 1932, in dem noch „wahrheitsliebende“ (S. 278) Richter agierten. Trotzdem wirkt es wie eine Vorahnung von 1933, also Hitlers Machübernahme, als sie angesichts des Staatsanwaltes im selben Prozess resigniert feststellt: „Tief fraßen schon faschistische Gedankengänge sich in die Köpfe ein.“ (S. 278).

Gleichsam als Anhang zu ihren Gerichtsreportagen aus der Zeit der Weimarer Republik finden sich zwei Texte aus dem Jahre 1949 über den Prozess mit Veit Harlan, dem Regisseur des antisemitischen Hetzfilms Jud Süß. In den beiden Texten kommt ihre Fassungslosigkeit darüber zum Ausdruck, dass sich ein großer Künstler wie Harlan zu einem solchen, von Goebbels gewollten üblen Machwerk hergeben konnte. Möglich wurde dies ihrer Vermutung nach nur deswegen, weil sich deutsche Künstler wie Harlan ins rein Ästhetische flüchteten. So versuchten sie allen ethischen und politischen Ansprüchen entkommen zu können.

11 Gabriele Tergit, inzwischen zur britischen Staatsbürgerin geworden, kehrte nach dem Kriege regelmäßig in ihre geliebte Heimatstadt Berlin zurück. Angesichts dieser Besuche scheint es, als ob in ihrer unverwüstlichen Heiterkeit der liberale Geist der Weimarer Republik noch weiterleben würde. Erfreulicherweise ist es wenigstens $\mathrm{zu}$ einer symbolischen Heimkehr der Schriftstellerin nach Berlin gekommen, denn unweit des „Potsdamer Platzes“ gibt es nun auch eine „Gabriele-Tergit-Promenade“. 